\title{
Las relaciones militares entre los Estados Unidos y América Latina. Crisis e interrogantes futuras**
}

\section{INTRODUCCIÓN}

Las relaciones militares entre los Estados Unidos y la América Latina han llegado a una situación de tirantez. Como consecuencia de los cambios en el ambiente geopolítico, de la falta de simetría en los asuntos interamericanos y de las iniciativas recientes de los Estados Unidos en cuanto a los derechos humanos y al control de los armamentos, las bases del sistema militar interamericano han caído en el desconcierto. "El sistema está en decadencia significativa y quizás mortal"1, en las palabras de una autoridad en esta materia.

Dicho sistema se ha fundamentado, hasta ahora, en los intercambios, la doctrina común y el concepto de seguridad colectiva hemisférica. Las páginas que siguen son una exploración de las razones de su decadencia y de las posibilidades en el futuro de las relaciones militares. Es importante advertir que Latinoamérica está experimentando un cambio importante desde el punto de vista geopolítico y que este cambio a su vez afecta la calidad de las relaciones militares. Una cuestión relevante es la pregunta acerca de la utilidad de las relaciones militares con naciones que sean marginales a la seguridad central de los Estados Unidos.

\section{Geo política Nacionalismo e Integración Nagional}

Conforme con los cambios en el ambiente internacional de bipolaridad a multipolaridad, las naciones de América Latina se insertan más directa-

* El presente estudio fue preparado para el Grupo de Estudio sobre las relaciones entre paises latinoamericanos, organizado por el Instituto de Estudios Internacionales de la Universidad de Chile en los años 1978 y 1979, con el auspicio de la Tinker Foundation, New York.

** Las opiniones que se expresan en este ensayo son del autor y no pretenden representar las del gobierno de los EE.uU.

${ }^{1}$ John Child, "The Inter-American Military System: Historical Development, Current Trends and Implication for us Policy", Military Issues Research Memorandum. Carlisle Barracks, October 23,1977, p. 33. Este artículo perspicaz se originó como contritribución a la conferencia "Seguridad Interamericana y los Estados Unidos" que se efectuo en el United States Army War College, 20-22 de enero de 1977 
mente en los asuntos internacionales. Una región que en términos globales ha sido históricamente "ni decisiva ni influyente", es más activa ahora en el sistema internacional. Los índices de esta interacción son varios: el movimiento comercial diversificado en la dirección Norte-Sur, pero también en grado creciente en la dirección Este-Oeste (Brasil hacia Africa, los países exportadores de petróleo de Levante hacia América Latina); las iniciativas en el derecho marítimo; la participación en las organizaciones internacionales; el desarrollo de algunos países como importantes exportadores de alimentos a la comunidad mundial; las fuentes de energía; el avance tecnológico; el activismo cubano en el Tercer Mundo; la posibilidad de proliferación nuclear; la difusión de poder militar convencional y la diversificación de las fuentes de armamentos.

Los índices de interacción son paralelos con otro movimiento global -el pluralismo ideológico-, o sea, el deseo de ensayar varias formas políticas, económicas y sociales para desarrollar estados nacionales más integrados. Ya se denominen democracias civiles (Venezuela, Colombia, Costa Rica), o reformismo militar de derecha, de tendencia corporativista y autoritaria (Brasil, Uruguay, Argentina, Chile, El Salvador, Guatemala y Bolivia), o de izquierda (Perú de antaño), o de estirpe menos definida (Ecuador, Honduras), o de partido único (México), o el socialismo cubano, hoy en día los gobiernos latinoamericanos son más participatorios, recaudan más impuestos, invierten más, construyen y educan más, producen más alimentos y en general articulan sus intereses nacionales dentro de la comunidad internacional mejor que en cualquier punto en su historia. Es cierto que la distribución de bienes y servicios aún es regresiva y pocos países han solucionado los dilemas que enfrentan todos ellos en su desarrollo, o sea, cómo maximizar la producción, la participación sociopolítica, y la redistribución económica simultáneamente, sin debilitar las bases que sostienen el gobierno.

Un nacionalismo nuevo, denominado desarrollista, caracteriza a América Latina. El desarrollo equivale a la integración social y a la seguridad nacional, en una correlación oportunamente designada "de causalidad mutua" por los brasileños. Puede significar también la adquisición de

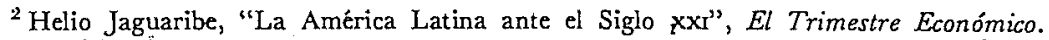
Vol. xLI (abril/junio 1974), p. 419. También véase los siguientes anảlisis sobre el dinàmico ambiente internacional latinoamericano: Riordan Roett, "The Changing Nature of Latin American International Relations: Geopolitical Realities", en Report of the Commission on United States-Latin American Relations, The Americas in a Changing World, N.Y.: Quadrangle, 1975; Roett, "Brazil Ascendant: International Relations and Geopolitics in the Late 20th Century", Joumal of Intemational Affairs, Vol. 29, $\mathrm{N}^{\circ} \mathbf{2}$ (Fall 1975); G. Pope Atkins, Latin America in the International Political System, New York: Free Press, 1977.
} 
poder nuclear, tanto como fuente de energía como para el desarrollo futuro de una potencia nuclear modesta. En suma, estas tendencias indican que se están estableciendo bases para estados nacionales más viables. El transcurso del tiempo indicará cuál de ellos desempeñará un rol más influyente en el mundo.

Este nuevo dinamismo internacional de América Latina coexiste con algunas de las formas tradicionales. Queda una zona económica y tecnológicamente dependiente y ninguna economía ha desarrollado la infraestructura y las tasas sostenidas de inversión interna necesarias para engendrar el crecimiento económico autónomo. La mayoría de los países manifiesta el desequilibrio urbano-rural en el cual grandes proporciones del pueblo no disfrutan del desarrollo. Las distancias entre los niveles de ingreso se ensanchan en vez de disminuir. Lo que esto significa para el desarrollo de sistemas políticos integrados es francamente negativo, porque, si la historia guía hacia el futuro, el aumento de los ingresos y de la satisfacción psicológica debe ser más uniforme. Políticamente, lo que presagia es la continuación de las casi eternas crisis de legitimidad, participación y distribución, que se expresan en gobiernos débiles e ineficaces que tratan de solucionar los problemas de desarrollo por medio de tecnocracias civiles-militares.

En los asuntos internacionales, la mayoría de los países latinoamericanos no tendrán un papel "ni decisivo ni influyente", porque exhiben sus debilidades internas en su política exterior. Sin embargo, es importante excluir de esta generalización a los siguientes países: Brasil, por su extensión territorial, población, recursos, base industrial, y por su gobierno de empuje desarrollista; Venezuela con su petróleo; México con algunos de los rasgos que tiene el Brasil, además de su riqueza petrolífera; y Cuba con su política extranjera revolucionaria y el apoyo decisivo de la Unión Soviética. En un nivel secundario pertenecen a este grupo Argentina, Chile, Perú y Colombia, con poblaciones y recursos considerables. Sin embargo, estos últimos se encuentran con problemas internos de tal tamaño que les impiden participar de modo influyente en los asuntos mundiales.

Un bosquejo subregional muestra un alto nivel de cambio geopolítico. En el Caribe, los recién nacidos microestados de habla inglesa y los otros en gestación no son capaces de hacer progresos sin ayuda exterior. Belice, que es codiciada por Guatemala y que quiere su independencia con el apoyo británico, posteriormente pone de manifiesto los límites de una presencia británica prolongada en el Caribe. Concurrentemente, algunos países caribeños están ensayando formas de socialismo propio, como el "socialismo democrático" de Jamaica y el "socialismo cooperativo" de Guyana - con el objeto de eliminar divisiones internas, incrementar 
la producción, y construir sociedades más integradas. Cuba, por virtud de su ubicación, su diplomacia activista, el apoyo soviético, su·intervención energética en los asuntos africanos, ha llegado a ser una potencia temida y respetada. A la vez, ha decidido desempeñar un rol moderado en la región del Caribe, prefiriendo relaciones correctas con los estados próximos en vez de exportar la revolusión subversiva. Así se proyecta como nación en desarrollo imparcial y hermana, ansiosa de socorrer el proceso de construcción nacional. Sin embargo, la imagen de Cuba como país desinteresado y que no quiere exportar la revolución pierde el lustre por razón de los lazos soviéticos y por su totalitarismo interno.

Conforme con sus ambiciones de desarrollo nacional y para asegurar las bases internas de sustento, los países del Caribe están diversificando sus enlaces internacionales. Pero es cada vez más evidente que, no obstante posturas de no alineamiento y un coqueteo casual con el bloque socialista, los EE.UU. todavía debe considerarse la fuente principal de inversiones de capital, de tecnología, de ayuda económica y el mercado principal para los productos de la región y para su mano de obra sobrante: Además, la retirada británica de la región y el papel incipiente de Cuba exigen que los Estados Unidos se esfuercen más para enfrentar los apremiantes problemas del Caribe en el contexto bilateral y multilateral. La administración Carter se ha mostrado dispuesta a tomar un papel más cooperativo en estos asuntos, un hecho puesto más de manifiesto por las recientes visitas de altas autoridades, tales como la esposa del presidente Carter, el embajador a las Naciones Unidas Andrew Young, y el ex subsecretario para Asuntos Latinoamericanos Terence Todman. Se debe subrayar que, aunque las relaciones de los EE.uU. con los otros países del hemisferio se han caracterizado por su tirantez en los últimos tres años, con los del Caribe están mejorando, con la excepción del caso especial de Cuba.

En otras partes del ambiente latinoamericano se vislumbran cambios de trascendencia geopolítica. En México, la administración de López Portillo se declara más resuelta en enfrentar los problemas internos de México y prescindir en parte del activismo tercermundista de su antecesor, el presidente Echeverría. México enfrenta la pregunta crítica de cómo maximizar los beneficios de su riqueza petrolera antes de que sus desequilibrios socioeconómicos internos lleguen a proporciones intratables, A causa de su creciente nivel de integración económicà y cultural con su vecino del norte, los problemas de México son automáticamente los de los Estados Unidos. La interdependencia de ambos países se demuestra por la migración indocumentáda y sus consecuencias. Los recursos hidrocarburantes — 44 mil millones de barriles de reservas confirmadas y 200 mil millones de reservas posibles- conducirán a México a ser un factor deter- 
minante en la coyuntura mundial, con una creciente capacidad de afectar la distribución de poderío en el sistema internacional.

En América Central, el ambiente político se identifica con la persistencia de sociedades en conflicto que tratan de modernizarse y simultáneamente evitar los concomitantes descoyuntamientos socio políticos. Gobiernos militares y autoritarios predominan con escasos éxitos en el logro de esta meta. Nicaragua en cierto sentido representa el prototipo de la situación política de toda la América Latina, esto es, un sistema político liberalizante encasillado en el sistema de autoridad tradicional y la existencia de partidos políticos con bases populares débiles. La transformación hacia una sociedad de más participación socioeconómica y política será políticamente traumatizante. El trauma a su vez afecta las relaciones con otros países. La guerra civil nicaragüense de 1978-79 demuestra bien las dimensiones internas e internacionales de este proceso*

En América del Sur existen amplios índices de la evolución de estados más eficaces y con mejor capacidad de articular los intereses nacionales. El impacto geopolítico se nota en el renacimiento de cuestiones fronterizas latentes, en la competencia por recursos del subsuelo y marítimos, y en los principios de esferas clásicas de influencias económicas, políticas y militares. En vísperas del centenario de la Guerra del Pacífico, en la costa oeste, Perú, Chile, Bolivia y en menor grảdo Ecuador y Argentina, discuten de nuevo la antigua cuestión de Tacna-Arica, la búsqueda boliviana de una salida territorial al mar. Al mismo tiempo los tres países tienen gobiernos militares que desarrollan sus respectivos programas de integración nacional: el corporativismo autoritario de Chile después del experimento socialista de Allende, el reformismo anteriormente radical del Perú, y la copia boliviana del modelo brasileño de desarrollo nacional.

Los mismos tres países, los cuales han logrado diferentes éxitos en sus respectivas políticas nàcionales, recién pusieron atención a sus asuntos extranjeros, un dominio donde los gobiernos militares son normalmente menos diestros y menos militantes. Argentina, según Chile, tomó una actitud muy intransigente en la cuestión del canal Beagle, donde los intereses en juego son potencialmente más grandes dada la presencia de krill y la presunta presencia de petróleo en los mares adjuntos. Sin embargo, la cuestión del Beagle, la disputa de fronteras entre Perú, Chile y Bolivia, y la disputa británico-argentina acerca de las islas Malvinas reflejan los rasgos de la política interna e institucional llevada a cabo por los respectivos gobiernos militares. En suma, sea para lograr objetivos políticos internos o para defender el patrimonio nacional en el ámbito internacio-

\footnotetext{
*Este trabajo fue preparado en marzo de 1979.
} 
nal, estos eventos indican que los gobiernos son capaces de movilizar el apoyo popular cuando se trata de amenzas a la seguridad nacional. Lo mismo se observa en las tensiones ecuatoriano-peruanas acerca de la cuestión de la zona fronteriza con sus yacimientos de petróleo. Colombia y Venezuela también se encuentran en desacuerdo acerca de la contigua plataforma continental, de la explotación de sus recursos, y acerca del movimiento de trabajadores colombianos a Venezuela.

Estos casos sirven para subrayar que la América Latina no es ya una región estratégicamente insignificante o de escasa importancia en el sistema internacional o en donde reina una perpetua tranquilidad. Por el contrario, el fenómeno más importante es la evolución del Brasil como la primera potencia regional con la capacidad de llegar a ser el primer país del hemisferio sur, y de lograr el rango de potencia mayor en diez o quince años. Reconociendo esta importancia, los EE.UU. firmaron el convenio de 21 de febrero de 1976 con el Brasil, con el fin de llevar a cabo consultas de alto nivel sobre asuntos internacionales de mutuo interés. Este memorándum constituye un reconocimiento por parte de los EE.UU. que el Brasil tiene la suficiente influencia internacional para permitirle funcionar como aliado en algunos ámbitos de asuntos internacionales, por ejemplo, en el Africa, el Levante y la América del Sur. La ascendencia brasileña ha intensificado la competencia tradicional con Argentina; por mucho tiempo su único competidor por el liderazgo latinoamericano. Argentina está bien distanciada en casi todos los índices de poder nacional y solamente en la tecnología nuclear está adelantada a su rival. Mientras tanto la expansión económica del Brasil se siente en los países lindantes - Uruguay, Paraguay y Bolivia-y en la penetración de mercados africanos.

\section{Los ee.uU. Y LA América Latina - Las asimet rías persistentes}

La culminación de este dinámico ambiente geopolítico -el nuevo nacionalismo, el activismo internacional y la reaparición de tensiones intraregionales- se impone justamente cuando los EE.UU. han decidido aflojar los lazos que lo han atado tan íntimamente con los países latinoamericanos. Este proceso se manifiesta más palpablemente en el reajuste de relaciones con Panamá por razón de los nuevos tratados acerca del Ganal. Sin .embargo, el asunto del Canal antecede una más amplia reconsideración y nuevos rumbos para la política estadounidense hacia América Latina y hacia todo el mundo bajo la rúbrica de los derechos humanos. Los EE.UU. otra vez se embarcan en suavizar deliberadamente su imagen en América Latina, como parte integrante de su anhelo de reconfigurar sus relaciones internacionales, de derrumbar el sistema rígido de los 
años después de 1945 y de reestablecerse como vocero de lós valores democráticos. Esta imagen perdió su lustre con Vietnam, Watergate y con la identificación de intenciones siniestras en la política estadounidense hacia el Tercer Mundo. En estos nuevos ensayos, los EE.UU. desean acabar con su inflexible preocupación con la amenaza soviética y repartir su atención más equitativamente hacia Europa Occidental, el Japón y el Tercer Mundo.

El proceso del cambio de imagen será difícil, si no imposible, para los EE.UU. por varias razones. Ha sido y será el principal poder económico, político y militar en el hemisferio. La región, históricamente, sirve para los EE.UU. como el campo de pruebas de varias iniciativas de su política extranjera: la doctrina Monroe, la diplomacia big stick, la seguridad colectiva, y de su entrada en los esfuerzos de construcción nacional en el Tercer Mundo. Los EE.uU, han tratado de construir una comunidad de naciones que tengan "una relación especial" con rasgos comunes tales como geografía, historia y algunas formas políticas. A cambio de esa "relación especial" - representada por la Organización de Estados Americanos y una cantidad de convenios interamericanos- los países latinoamericanos han apoyado, en su mayor parte, la política extranjera de los EE.UU. La relación desigual entre la superpotencia del norte y los débiles y dependientes paísés latinoamericanos hizo bien fácil mantener el mutuamente conveniente mito de la "relación especial". Con la evolución del mundo multipolar, con la evolución de nuevas formas de poder que residen en la posesión de recursos económicos de alta demanda y con la decreciente utilidad de formas rudas de disuasión en las relaciones internacionales, los países latinoamericanos en el futuro tendrán más flexibilidad en la conducta de sus asuntos exteriores. Se precisará de cierto tiempo para que esta nueva condición sea aceptada por todos y llegue a arraigarse.

A estos cálculos debe añadirse la asimetría que caracteriza las relaciones interamericanas. Mientras se la considera en relación especial, en verdad la región tiene una importancia menor en la política exterior de los EE.UU. y esa importancia tal vez decline en comparación con otras regiones. Algúnas estadísticas sostienen estos cálculos. En el comercio exterior, los EE.uv. tenían en América Latina $\$ 22,2$ mil millones de sus $\$ 133,1$ mil millones de inversiones extranjeras cumulativas. Europa Occidental tiene más comercio con América Latina que lós EE.uU., cuyas exportaciones bajaron del 39 al $31 \%$ de las importaciones regionales entre 1960 y 1975 . Además, el total de importaciones y exportaciones estadounidénses que derivan de América Latina constituyen menos del $0,5 \%$ del producto nacional bruto de 2,5 trillones. En materias estratégicas, Venezuela abastece 
alrededor del $15 \%$ del petróleo importado ${ }^{3}$. México, a su vez, abastecerá un creciente porcentaje y será un factor importante en un mundo petropolar. Otras materias son importantes, pero con la excepción de petróleo no hay materias estratégicas en América Latina que no se puedan adquirir en otros lugares.

El acceso a recursos estratégicos y el nivel de intercambio comercial no son suficientes para determinar la importancia relativa de la región. América Latina es importante para los EE.UU. porque, en términos militares, es una región de "economía de fuerza". Básicamente, los EE.uU. quieren que allí no aparezcan graves problemas que requieran la atención y los recursos que deben usarse en otras partes, o sea, un ambiente de mínimos riesgos para su seguridad. En términos más filosóficos, EE.uU. "desea gobiernos legítimos y fuertes que respondan adecuadamente a las aspiraciones populares, y no la estabilidad propia... gobiernos representativos que defienden sus intereses ampliamente y justamente" Entonces, no obstante su importancia en términos filosóficos, América Latina ocupa un lugar secundario para los EE.UU.

Si para los Ee.uU. la importancia de América Latina está declinando, lo contrario no es verdadero. Abraham Lowenthal, un estudioso de asuntos interamericanos declara:

Las relaciones interamericanas son fundamentalmente asimétricas.

Lo que es importante para la América Latina puede ser marginal en Washington, o lo que se percibe ventajoso en Washington puede parecer explotativo en la América Latina. Con esta asimetría la tirantez es inevitable.

$Y$ añade:

La formulación de su políticà latinoamericana goza de un carácter especial, distinta de la formulación de la política hacia los países industiralizados, y deriva de la confluencia de importantes intereses económicos, de intereses de seguridad de poca importancia, y pocas otras razones para justificar una mirada prolongada por parte del gobierno. Los asuntós latinoamericanos rara vez reciben atención de alto nivel....

Las reflexiones francas del presidente Carter acerca de los nuevos tratados sobre el Ganal de Panamá —uno de los más importantes temas de la

${ }^{3}$ Las anteriores estadisticas se extraen de us Council on International Economic Policy, Intemational Economic Report of the President, us Government Printing Office, 1977.

${ }^{4}$ Albert Fishlow, Debt, Growth, and Hemispheric Relations: Latin American Prospects in the 1980s, manuscrito inédito, Berkeley: University of California, 1977, p. 55.

5 Abraham Lowenthal, "The Making of us Policies Toward Latin America", Latinamericanist, Vol. 10, No 1 (November 18, 1974), p. 4. 
política internacional latinoamericana de los últimos años-- expresan un sentido semejante a Lowenthal:

Fue la empresa política más difícil de mi vida, incluso la campaña presidencial misma. Y para lograr un voto de dos tercios (favorable) en el Senado en torno de una cuestión que no tiene ningún beneficio político positivo, pero bastantes repercusiones políticas negativas en algunos estados, fue una muestra impresionante de valor por parte del Senado de los EE.UU. ${ }^{6}$.

El investigador chileno, Luis Maira, escribió en la revista mexicana Estados Unidos: Perspectiva Latinoamericana, a principios de 1977, que la Administración Carter tendría dificultades en formular una política latinoamericana consistente. Atribuía esto a la descentralización burocrática, a la reducida importancia que tiene la región en la política extranjera estadounidense y a las divisiones ideológicas dentro de su partido Demócrata ${ }^{7}$.

\section{LAS RELACIONES MILITARES ENTRE LOS EE.UU. Y LA AMÉRIGA LATINA. PASADO, PRESENTE Y FUTURO}

Las asimetrías se demuestran claramente en la evolución de las relaciones militares. Generalmente se concede que América Latina desempeña un papel limitado en la estrategia militar de los EE.UU. Sin embargo, los estrategos militares han tratado de definir el valor de la región en relación con las exigencias militares de los EE.UU.: por ejemplo, prevenir el establecimiento de bases e influencias enemigas; mantener el acceso a las líneas de comunicación y a los recursos estratégicos y las bases; y prevenir el. conflicto intrarregional ${ }^{8}$.

Fuera del requisito de estacionamiento de fuerzas en la Zona del Canal y de la administración de los programas de asistencia militar, las fuerzas militares de los EE.UU. se conservaban para partes más críticas del mundo. La seguridad colectiva, que evolucionó de la postura hemisférica contra el

\footnotetext{
${ }^{6}$ President James Carter, Question and Answer Period with Senior Editors, September $22,1978$.

${ }^{7}$ Luis Maira, "Estados Unidos y América Latina: ¿Perspectivas de Cambio bajo la Administración de Carter?" en Cuademos Semestrales, Vol. 1 (Abril 1977), pp. 49-77; publicación semianual de la revista mensual Estados Unidos: Perspectiva Latinoamericana del Centro de Investigación y Docencia Económicas, Ciudad de México.

${ }^{B}$ Un excelente ejemplo de este tipo de análisis es Raymond A. Komorowski, "es Strategic Interests in Latin America and the Impact of the Nato Short War Strategy", Military Issues Research Memorandum, Carlisle Barracks: Strategic Studies Institute, July 29, 1977.
} 
Eje consagrada en el Tratado de Asistencia Recíproca de 1947 y que después se convirtió en una alianza anticomunista, constituyó el sistema que suscitó una serie de relaciones político-militares bilaterales y multilaterales.

A través de estos enlaces, que se formalizaron en convenios de asistencia militar, los EE.UU. vinieron a ser la fuente principal de doctrina militar, de armas y de entrenamiento. Las relaciones también tenían importantes ramificaciones políticas: servían para alinear sólidamente las instituciones militares en apoyo de la Alianza Atlántica. Además, los Ee.uU. creían que por medio del entrenamiento conducido bajo su auspicio y la exposición a un sistema militar moderno, los militares serían anticomunistas, más profesionales, permanecerían apolíticos y así ayudarían a establecer las bases para la democracia política. Ocurre que los militares latinoamericanos son anticomunistas por razones institucionales y culturales y que al aumentar su profesionalismo y exponerlos a sistemas extranjeros pudo haber incrementado su propensión hacia el activismo político a costa de sus colegas civiles ${ }^{9}$.

Bajo el sistema de seguridad colectiva se entendía que EE.UU. defendería el hemisferio contra una amenaza extracontinental. Además, se podía esperar que los EE.UU., por medio de su influencia en el sistema interamericano, mediara los conflictos regionales. Al mismo tiempo los latinoamericanos veían sus relaciones con la superpotencia con ambivalencia: se consideraba a los EE.UU. un protector contra la amenaza extracontinental y "una amenaza por sí misma"10 contra los intereses nacionales latinoamericanos. Resultó que en los casos en que los EE.UU. sentían sus intereses vitales directamente amenazados, y en que la maquinaria de seguridad colectiva de la Organización de Estados Americanos era demasiado ineficaz, los EE.UU. actuaron unilateralmente, es decir, en Bahía Cochinos (1961), en la crisis de los misiles en Cuba (1962) y en la República Dominicana (1965).

La asimetría influía en la manera cómo ambos lados percibían la amenaza. Mientras los EE,Uu. consideraban grave el surgimiento de amenazas internas que pudieran producir ambientes propicios para la prolifera-

${ }^{9}$ Sobre este punto, véase John S. Fitch, "The Political Consequences of us Military Assistance to Latin America", Military Issues Research Memorandum, Carlisle Barracks: Strategic Studies Institute, October 15, 1977; y su The Military Coup d Etat as a Political Process, 1948-1966, Baltimore: Johns Hopkins University Press, 1977.

${ }^{10}$ John Child, "Alliance Theory and the Organization of American States", manuscrito inédito. 1974; contenido en Child The US-Latin American Strategic Relationship, colección de documentos, 1965-77, depositada en la biblioteca del United States Army War Gollege. 
ción del comunismo, los latinoamericanos se preocupaban igualmente por la violación de sus soberanías por parte de los EE.UU. y los otros países. Consideraban el Tratado de Rio y la Organización de Estados Americanos "no principalmente como una alianza contra la amenaza externa sino como una detallada estructura jurídica y moral para limitar la intervención de los EE.UU. en el hemisferio"11.

Recientemente, la asimetría se expande a percepciones de la amenaza además de la definición del concepto de seguridad. Los latinoamericanos han promovido el concepto de la seguridad económica dentro de una definición más amplia de seguridad nacional y de integración nacional, mientras que los EE.UU. se muestran poco dispuestos a discutir la seguridad económica colectiva en los foros interamericanos. En el protocolo de San José (1975) añadieron la especificación "que no acepta obligación alguna de negociar, firmar, o ratificar cun tratado o convenio acerca del tema de la seguridad económica colectiva".12. El secretario de Estado Henry Kissinger criticó firmemente el nuevo anteproyecto de la carta de la Organización de Estados Americanos en razón de sus disposiciones sobre la seguridad económica colectiva: "Lamento decir que es algo que nuestro gobierno no puede ni firmar ni recomendar para que nuestro Senado lo ratifique. Contiene disposiciones y exhortaciones de principios generales que son mal definidas y on miniosas"13.

Dentro del sistema de seguridad colectiva, las relaciones militares evolucionaron en un cuerpo de organizaciones, doctrina y entrenamiento comunes que no equivalía a una visión común del mundo y a una percepción mutua de la amenaza y de la seguridad. John Child asevera que la cooperación militar tomó los rasgos de un sistema militar interamericano, que aunque no califique como una entidad completamente articulada e integrada, sin embargo tiene importantes componentes y funciones y "merece considerarse porque individuos de relevancia política e instituciones en las Américas han reconocido su existencia y se han preocupado por sus propósitos y vigor"14.

Los componentes del sistema han sido los siguientes: la Junta Interamericana de Defensa, fundada en 1941 y la más antigua organización militar multilateral en que participan los EE.UU.; el Tratado Interame-

${ }^{11}$ Ibid., p. 8.

${ }^{12}$ Citado en G. Pope Atkins, "Mututal Security in the Changing Inter-American System: An Appraisal of OAS Charter and Rio Treaty Revisions", Military Issues Research Memorandum, Carlisle Barracks: Strategic Studies Institute, July 25, 1977, p. 18.

${ }^{13}$ Ibíd., p. 19.

${ }^{14}$ John Child, "The Inter-American Military System...", p. 2. 
ricano de Asistencia Recíproca; los programas de asistencia militar; el Colegio Interamericano de Defensa; los especialistas militarè en asuntos latinoamericanos en los EE.uU.; el Consejo de Defensa Centroamericana; las conferencias hemisféricas de los estados mayores; maniobras y ejercicios conjuntos como los ejercicios navales UNITAS; medios de comunicación multinacional; programas de adiestramiento militar en Panamá $y$ en los EE.Uu.; y el fracasado ensayo de establecer una fuerza de paz interamericana. En estos días se está cuestionando la utilidad de los diversos componentes.

Junto con estas organizaciones e instituciones, las relaciones militares incluían conceptos estratégicos comunes. Estos, en su mayor parte derivadas de la segunda guerra mundial y de la guerra fría, se convertían cada vez más en puntos controversiales que dieron lugar a la debilitación del sistema militar. Los latinoamericanos se opusieron a la idea de desarrollar un sistema formal de seguridad colectiva que apareciera como si hubiera sido propuesto por los EE.UU. El comunismo monolítico se percibía como la amenaza principal durante las décadas del cincuenta y sesenta, pero los latinoamericanos no estaban totalmente de acuerdo con esta percepción y resintieron el hecho que los EE.UU. los descuidaban en favor de los aliados europeos y asiáticos.

El consertso en favor de un sistema militar interamericâno culminó en los años en que Fidel Castro exportaba la revolución. Surgió una amenaza creíble con el atentado cubano de convertir a los Andes en la Sierra Maestra. El resultado de esto fue el desarrollo de un concepto estratégico más amplio y de un alto nivel de cooperación militar entre los EE.uU. y América Latina. La defensa interna y el desarrollo constituyeron la estrategia para combatir el comunismo revolucionario. Este consenso surgió cuando los EE.UU. entraron en un período de activismo frente a la marcha indómita de la expansión comunista en el Tercer Mundo como fue percibido en Vietnam y en la República Dominicana. Por este motivo se establecieron programas de desarrollo como la Alianza para el Progreso, con los que se intentaban establecer las bases de democracias liberales que servirían como alternativas al comunismo.

Durante esta época los EE.UU. y numerosos países latinoamericanos elaboraron impresionantes programas de contrainsurgencia y acción cívica para enfrentar los focos guerrilleros. Las organizaciones multilaterales existentes experimentaron nuevo impulso y se crearon otras como el Colegio Interamericano de Defensa y un comando unificado en la Zona del Canal de Panamá. La cooperación militar logró su apogeo durante el período 1959-67, aunque la amenaza revolucionaria cubana no era percibida universalmente. Retrospectivamente, se puede decir que 
los EE.UU, sobreestimaron la vulnerabilidad de las sociedades latinoamericanas a la revolución ${ }^{15}$.

Ha bajado bastante el consenso favorable acerca de la utilidad de las relaciones militares interamericanas. Las razones son varias. En 1965, EE.UU. de nuevo mostró su propensión unilateral en la intervención dominicana. Además, Vietnam ocupaba la atención norteamericana y América Latina se sometía a la política de presencia discreta durante las administraciones de Nixon. Al mismo tiempo evolucionaban las doctrinas de seguridad en la integración sociopolítica nacional: la doctrina brasileña desarrollada en la Escola Superior da Guerra y la doctrina radical de reforma socioeconómica impulsada en el Centro de Altos Estudios Militares de Perú. Los modelos brasileños y peruanos son tal vez las ideas latinoamericanas más innovadoras de la época moderna. Ambos conceptos, adaptados en varias formas en otros paises, definen la seguridad nacional en términos de la integración y desarrollo económico, o sea, una nación carece de seguridad si no tiene estos atributos socioeconómicos. Los futuros líderes de América Latina, de los cuales muchos se entrenarán en análogos ambientes cívico-militares, compartirán estos mismos conceptos. Las nuevas doctrinas de seguridad nacional aparecieron juntamente con la teoría de dependencia como explicaciones de la ubicación marginal de América Latina en los enlaces militares internacionales $^{16}$.

Al mismo tiempo, el intento de establecer democracias liberales cedía a la aparición de gobiernos militares de tendencia nacionalista y desarrollista, fuertemente convencidos que era su responsabilidad reformar y construir sus naciones. Otra tendencia, el pluralismo ideológico, con su más amplia tolerancia hacia los intentos reformistas radicales, surgió: como el experimento socialista en Chile y la revolución peruana. El milagro económico brasileño mostró las posibilidades significativas del modelo militar-tecnocrático autoritario para promover el desarrollo. En suma, al empezar la segunda mitad de la década del setenta se veía bastante claro que los países latinoamericanos estaban dando importantes pa-

${ }^{15}$ Orra tesis de la exportación de la revolución por parte de Cuba es la expansión defensiva: para defender la revolución internamente y contra los EE.UU., Cuba decidió crear situaciones revolucionarias en América Latina para distraer la atención y los recursos norteamericanos. Se puede decir lo mismo acerca de las expediciones cubanas en Africa. La tesis es atrayente $e_{2}$ pero no explica suficientemente bien la política extraniera cubana.

${ }^{16}$ El distinguido pensador militar peruano general Edgardo Mercado Jarrín declara que la tecnología de la guerra moderna hace de la producción industrial un factor determinante en el poder nacional. Opina que la dependencia más tiránica es la de dependencia militar tecnológica. Oiga (Lima), 15 de marzo, 1974, pp. 18-20, 44-46. Citado en David Ronfeldt y Cesar Sereseres, U.S. Arms Transfers, Diplomacy, and Security in Latin America and Beyond, Santa Mónica: Rand Corporation, October 1977, p. 15. 
sos institucionales y programáticos en gobierno efectivo, aunque, existieran indicaciones contrarias.

Al empezar la década del setenta surgieron importantes cambios en la transferencia de armas. En los EE.UU, los inhibidos congresistas empezaron la política de limitar las ventas de armas en la América Latina, una región que normalmente constituye una parte minúscula del mercado mundial de armas. Además, la legislación prohibía la venta de armas norteamericanas avanzadas en la región. Estas inhibiciones se combinaron con el hecho que -los EE.uU. no tenían la diversidad de armamentos deseada por los clientes latinoamericanos durante este último ciclo de compras ${ }^{17}$. El impacto más duradero de estos acontecimientos es que los EE.UU. no son la fuente principal de armas para la región (Francia ha sido el vendedor principal desde los primeros años de la década, los soviéticos rompieron el monopolio occidental en Perú, e Israel rivaliza con los Ee.uU. en la actualidad). Por eso cualquier influencia política que tuvieron los EE. UU. con respecto a la transferencia de armas está disminuyendo. Se nota también el nacimiento de industrias indígenas de armas con capacidad exportadora en Brasil y Argentina.

Recientemente otros factores han sido determinantes: el más notable es la preocupación por los derechos humanos codificadas en la legislación del Congreso y reafirmados en la política exterior de Carter. Las consideraciones de derechos humanos que se insertaron en la ley de Asistencia de Seguridad Internacional y de Control de Exportaciones de Armas de 1976 prohiben la asistencia militar a gobiernos que violan brutalmente los derechos humanos de sus ciudadanos. También se requiere el visto bueno del Congreso en casos de ventas de armas superiores al valor de US\$25 millones. Siendo los derechos humanos un enfoque de la política exterior carteriana los países con reputaciones negativas en ese aspecto - Argentina, Brasil, Chile, El Salvador, Guatemala, Nicaragua, Uruguayexperimentaron el cese de ayuda militar en forma de subvenciones y de créditos. La situación imperante a comienzos de 1979 era la siguiente:

Nicaragua -toda ayuda suspendida, 22 de septiembre, 1978; terminación completa, 8 de febrero, 1979.

Guatemala -rechazó toda forma de ayuda en 1977; existe un programa de entrenamiento por valor de $\$ 250.000$ para 1980 .

EL SALVAdor — suspensión desde 1978.

${ }^{17}$ Véase el perspicaz análisis de las tendencias corrientes en la transferencia de armas en Norman M. Smith, "Conventional Arms Transfers to Latin America", Military Issues Research Memorandum, Carlisle Barracks: Strategic Studies Institute, August 8, 1977. 
CHILE - terminación en 1976; sigue recibiendo armamentos hasta 1981 por compras anteriores.

ARgentina - todo terminado, 30 de septiembre, 1978; ninguna forma de ven tas o entrenamiento.

URUGUAY - limitadas compras de A-37; prohibición de subvenciones y créditos en 1976.

BRASIL - rechazó subvenciones y créditos en 1977; puede hacer compras. comerciales.

El impacto de la política de derechos humanos sobre las relaciones político-militares ha sido dramático. Con excepción del caso nicaragüense, los seis países citados o terminaron unilateralmente los convenios de asistencia militar con los EE.UU. o rechazaron la asistencia norteamericana y generalmente asumieron una posición muy intransigente acerca de la continuación de la cooperación militar. Los brasileños, que además reaccionaban contra el desagrado norteamericano con el acuerdo alemánbrasileño para la transferencia de tecnología nuclear, se retiraron de la Comisión Militar Norteamericano-Brasileña en 1977. Los argentinos cancelaron su participación en los ejercicios navales hemisféricos. Razonaban los diversos países que los EE.UU. habían escogido una postura selectiva y moralmente inconsistente. Sostenían también que se les trataban con desprecio porque no ocupaban posiciones de importancia estratégica en la lógica de la seguridad nacional norteamericana, como en los casos de las Filipinas y Corea del Sur, que han sido tratados de manera excepcional por los EE.UU.

La perspectiva latinoamericana acerca de los derechos humanos es bien distinta. Mientras EE.uU. se preocupa por los derechos humanos - una aseveración no completamente persuasiva porque creen que las metas son otras, como el consenso interno en torno de la política extranjera en los EE.UU. y el imperativo concomitante de acrecentar su ventaja vis-avis la Unión Soviética- ellos creen que a los EE.UU. no les importa la violación de los derechos individuales y colectivos de sociedades que conducen guerra interna contra guerrillas marxistas. Además, acusan a los EE.UU. porque no reconocen los problemas de sociedades que enfrentan las inevitables tensiones y la violencia que emanan del proceso de desarrollo. Ven una forma de intervención moral que no es enteramente altruista y que sirve propósitos ajenos.

Estas iniciativas de los EE.UU. han contribuido a los problemas en las relaciones político-militares. Algunos países se sienten abandonados por los EE.UU. precisamente cuando las amenazas internas y externas son más cré́bles que en los primeros años de la década del 60. Los logros soviético-cubanos en Angola y Etiopía y la estrategia de "intervención por 
invitación" han suscitado sospechas en el Cono Sur acerca de la creciente presencia naval soviética en el Atlántico del Sur y en el Caribe sobre las intenciones cubanas ${ }^{18}$. En los últimos años se rumorea la formación de una alianza defensiva entre Argentina, Brasil, Chile, Uruguay y Africa del Sur. Es una posibilidad remota ${ }^{19}$, pero estas perspectivas indican que los latinoamericanos toman en serio estos acontecimientos y están dotados de una capacidad, tal vez limitada, de emprender.iniciativas regionales que a la larga no servirán los intereses de los EE.UU.

Parece que loS EE.UU. se empeñan en reformar sus relaciones internacionales, desmantelar el sistema rígido que ha evolucionado desde 1945 y reafirmar su legitimidad como campeón de valores democráticos. Este país está tratando de liberarse de la preocupación inflexible que tenía frente a la amenaza soviética y poner su atención más equitativamente en la Europa Occidental y el Japón, y establecer más influencia en el Tercer Mundo. La historia de estos primeros ensayos en la América Latina manifiesta éxitos y derrotas. Los EE.UU. han reestablecido relaciones cooperativas con los países "socialistas" del Caribe que tienen apremiantes problemas económicos, Guyana y Jamaica. Sin embargo, en América del Sur persisten relaciones tirantes con países influyentes, notablemente con Argentina, Brasil y Chile. Por su carácter excepcional los recién ratificados tratados del Canal de Panamá, no son indicaciones válidas de éxito o de fracaso en la política latinoamericana. Son en realidad una in dicación de la problemática de los asuntos interamericanos en el proceso de la política extranjera estadounidense.

La política extranjera de derechos humanos no necesariamente difunde la democracia; puede en cambio darle vigor a las fuerzas antidemocráticas y así, en realidad, obstaculizar el proceso democrático. La gestión de promover derechos humanos en Brasil puede tener el resultado de convencerle más para adquirir la tecnología nuclear y aun de galvanizar el apoyo popular del gobierno, reduciendo así las oportunidades de lograr

${ }^{18}$ Los despliegues al extranjero de fuerzas de combate cubanas han suscitado temor en el contiguo Caribe sobre intenciones agresivas y por la probabilidad de asistencia militar cubana a países socialistas hermanos, a través de intervención por invitación. Este autor sostiene que estas posibilidades son remotas porque: Cuba no ha establecido suficiente identificación con un grupo marxista-socialista en condición de pedir asistencia; 'no existe en el Caribe un vacio de poder que podría explotar Cuba sin que los Ee.uv. reaccionara inmediatamente.

${ }_{19}$ Principalmente porque no existe la necesidad para tal organización que además tendria una capacidad militar muy reducida. Véase Margaret Daly Hayes, Brazil and the South Atlantic: Changing Perspectives on an Emerging Issue. estudio preparado para el Seminario sobre Brasil y el Atlántico Sur en el School of Advanced International Studies, Johns Hopkins University, 14 de marzo, 1978. 
la meta loable de controlar la proliferación nuclear y de promover la liberalización política.

Brasil, ya sea que realmente logre ser una entidad más integrada con los rasgos económicos y militares de una potencia importante o no lo consiga, desafiará la inventiva de la diplomacia político-militar estadounidense. Ya percibe un papel mayor en América del Sur y Africa y goza de la capacidad de ser un aliado de los EE.UU. Se está acercando a tener una capacidad impresionante de vigilancia marítima. Será además un factor político-económico en las zonas contiguas de la América del Sur y podrá desempeñar un papel importante como mediador entre el Tercer Mundo y los países industrializados. También podrá adquirir una modesta capacidad nuclear para fines del siglo, lo cual tal vez estimula a Argentina a hacer algo igual. Será imperativo para los EE.UU. mantener comunicaciones con la institución militar mientras Brasil evoluciona como una fuerza más impresionante en el sistema internacional bajo la dirección de un gobierno predominantemente militar.

\section{ConcLusiones}

En el futuro próximo, América Latina experimentará importantes cambios geopolíticos: la evolución de gobiernos fuertes y eficaces, la competencia para el desarrollo de los recursos naturales, el resurgimiento de las antiguas rivalidades regionales y de las tensiones fronterizas y la difusión del poder militar con la posibilidad de la proliferación nuclear. En suma, estas tendencias indican que la América Latina se independizará más de las preferencias de la política extranjera estadounidense. Por cierto, la multipolaridad engendrará el aflojamiento de las alineaciones tradicionales, una condición que permitirá más flexibilidad a los países latinoamericanos. Es tal vez un acontecimiento inevitable; sin embargo es necesario mantener un ambiente que permita cooperar para lograr objetivos comunes.

Varias conclusiones son posibles. Si los EE.UU. quieren mantener relaciones útiles con las instituciones militares latinoamericanas, tendrán que prepararse para articular sus intereses de seguridad más ampliamente y adecuarse a los conceptos latinoamericanos de seguridad nacional. La definición ha sido frecuentemente poco pertinente al ambiente latinoamericano. Además, el propósito de relaciones. militares es poco entendido. La institución militar es una fuerza centrà en la política nacional y continuará siendo así en la mayor parte de los países en los próximos años, aunque algunos han anunciado planes para la transición a gobiernos civiles. Al mismo tiempo, se debe entender que un abrazo entusiasta a 
los gobiernos militares y a su eficacia política puede ser contraproducente porque son gobiernos con bases de apoyo muy estrechos.

A medida que la política internacional se vuelva más compleja, las naciones, no obstante sus tamaños, eyolucionarán en sus requerimientos militares. Si los EE.Uu. desean tener aliados con capacidades que permitan reducir los riesgos a su seguridad, entonces es conveniente reconocer esta realidad. Considerando la actitud del Congreso, la decisión de promover los derechos humanos y el control de armamentos, y la importancia marginal que tradicionalmente se da a los asuntos latinoamericanos, es dificil ver como EE.UU. responderá a las mínimas necesidades militares. Por eso, debe prepararse para tratar con un complejo de relaciones de seguridad en las cuales no será él la única fuente de asistencia militar. Puede en parte lograr esto si alienta el movimiento para limitar la adquisición de armas, tal como lo favorece la Declaración de Ayacucho de 1974 y las recientes llamadas mexicanas para fines semejantes. En fin, deben hacer más clara su política extranjera, hacerla más universal, para que los países latinoamericanos puedan anticiparla adecuadamente y respetarla como política equitativa.

Las diversas preguntas sobre la asistencia militar, su influencia política y el profesionalismo militar deben investigarse de nuevo. Por ejemplo, $\dot{¿}^{\text {en }}$ qué dirección va la influencia que conlleva la asistencia militar? ¿Qué tipo de influencia engendran las relaciones entre las correspondientes instituciones militares? La creencia ingenua de que los militares resultan profesionales iguales a sus pares norteamericanios ha causado problemas a los EE.UU. Estas formulaciones unilineares no servirán en un mundo multipolar.

Las relaciones militares deben justificarse en el sentido político. $\mathrm{Si}$ existen desacuerdos mayores de carácter político o económico, esto se refleja en las relaciones militares. Mientras existan cuestiones mayores y de un carácter divisivo las relaciones militares no serán tan cooperativas, especialmente si los líderes militares son a la vez gobernantes. Lo que se prescribe en este ensayo no es totalmente audaz. Los EE.UU. deberían tomar medidas para detener el alejamiento y elevar las relaciones militares con América Latina a un nivel político más alto. Con Brasil, reconociendo su relieve, debería iniciarse el establecimiento de un foro para consultas periódicas a nivel político-militar sobre temas de mutuo interés. Puede desarrollarse el mecanismo del memorándum de entendimiento firmado por los dos países en 1976. Sería apto considerar tal foro para la comunidad interamericana en su totalidad. Si no se detiene el proceso de alejamiento, afirma una autoridad eminente: "la posibilidad de una América Latina hostil, no cooperativa, y resuelta a utilizar sus recursos nacionales y tácti- 
cas de presiones internacionales como manera de negociarse mejor tratamiento por parte de los Estados Unidos, no puede descartarse completamente $^{\prime 20}$. El alejamiento, a la larga, puede también nutrir las fuerzas irracionales de un nacionalismo que impediría la cooperación.

${ }^{20}$ Caesar Sereseres, "The Future of us Military Diplomacy in the Hemisphere", Military Issues Research Memorandum, Carlisle Barracks: Strategic Studies Institute, November 11, 1977, p. 15. 